Vol. LXVI 2015

\title{
IMPORTANCE AND ROLE OF COMPETENCE IN PROFESSIONAL CAREER OF PRODUCT DEVELOP ENGINEERS
}

\author{
MILTENOVIĆ Aleksandar \\ Faculty of Mechanical Engineering, Department for design, development and engineering, University of Niš, \\ Niš, Serbia, aleksandar.miltenovic@masfak.ni.ac.rs \\ BANIĆ Milan \\ Faculty of Mechanical Engineering, Department for design, development and engineering, University of Niš, \\ Niš, Serbia, milan.banic@outlook.com
}

\author{
MILTENOVIĆ Vojislav \\ University of Niš, Niš, Serbia, vojamiltenovic@yahoo.com
}

\begin{abstract}
Product development is a creative task where is systematically created a new product, which makes possible to firms to offer attractive, innovative and market oriented products. In conditions of fierce competition and saturated markets, companies that do not innovate are stagnating and disappear from the market. Innovation is therefore every intervention which can reduce production costs, enables optimum utilization of available human, energy and material resources, improve product quality, improve the placement, which leads to an increase in competitiveness. A prerequisite for fulfillment of the above-mentioned tasks is that the companies have engineers with the appropriate competencies, which are able to, through creativity, innovation and fascinating technique of creating new or improving existing products and lunch it on the market. The paper discusses the role and importance of the competences that are necessary for a successful professional career of product development engineers.
\end{abstract}

Key words: competence, product development, innovations, professional career

\section{Introduction}

A company success in modern conditions is possible to achieve by introducing innovative products and product processes. Therefore application of innovative products and product processes is very complex and demands new work approach, which is primarily related to resource optimization, precision defining of competence and cooperative work approach.

Individual decisions are rare and usually risky because the performance advantage of the creativity and experience of a single person is less. Because of this, the tendency is to make decisions in groups and teams and to seek solutions to complex problems. A person's ability to work effectively in a team come more and more to the fore, since the role of the team in a company is growing.

Future market determines the strategy of planning products and process. Starting from the strategy of the company analyzed the potential for new business, identify ideas for new products and processes, and develop and evaluate product concepts. The result of the strategic planning of products and processes are development of new innovative products, their production and market launch.

Modern companies must have access to comprehensively educated engineers so that they can solve complex problems.

\section{Innovations and Corporate Strategy}

Innovations are very important factor for surviving the company on the market because companies need to increase their competitive ability throught:

- development of new high quality products,

- introduction of new technologies in production,

- introduction of new organisation in production,

- obtaining new markets and establishing new market relations,

- introduction of new methods of managing,

- introduction of new information and communication techniques etc 
The term innovation is usually limited to:

- Product innovation, which refers to the development and successful introduction of new ie substantially altered products and / or services;

- Process innovation, whose primary goal is the reduction of costs (especially manufacturing), but may be of decisive importance for obtaining weather or flexible benefits.

The primary objective of the innovation process is the design, development and successful launch of products and services in the areas in which the company deals. Product and process innovations are not independent of each other, but are closely linked.

Innovations lead to significant changes related to technology development, market, mode of delivery and organization of the companies. If these changes are very pronounced than it is about radical innovation. If it leads to minor changes compared to the previous situation, it is about evolutionary innovation.

Every innovation stems from ideas (invention) and each invention is a rule of ideas. This is mainly a general approach. In this concept it refers to the imagination of new products, new services or new processes. The idea is thus a manifestation of new, which have every innovation.

The idea can not be reached directly, but it develops the creativity that is obtained as a result of a systematic search. Radical innovations on world level amounts to only $10 \%$ and they are not so frequent. Many of the ideas that are the basis of evolutionary innovation, can be reached relatively easy to come by (looking competition, research of customer preferences, etc.).

Over $70 \%$ of business ideas originating from professional or private sphere of relevant persons and were either obvious or they can easily be accessed associatively.

Radical innovations are often built on ideas with a high degree of novelty, non-obvious or clear, rather they are the cause of surprises. Partial phases of finding ideas can be expressed as a methodical process supported.

Product and service have to exist to ensure the competitiveness of products. The goal is to early identify the potential for future success and to develop it in time. With the help of strategic product and process planning it can be possible to systematically complete this challenging business task. New sales potential will be recognized through continuous innovation in interaction with the market.

The cycle of strategic product planning is divided into phases:

- potential determination,

- product and process determination,

- product and process design,

- business planning.

Thereby, the cycle cannot be understood as a mere sequence of individual steps. Rather, the stages are run through iterative.

\section{Authoritative Competences of Product Development Engineers}

\subsection{Profiles of engineering competences}

The competences have the most important role in the development of human resources. Competence development is primarily related to the education but also to acquire knowledge and skills during a professional career. Very important impact on the successful execution of tasks in the workplace and survival of firms in modern conditions have understanding, identification and correct identification of competencies. There are several different definitions of competence:

- The basic unit in the development of human resources and communication in organizations is partly related to the performance, efficiency and effectiveness.

- Ability to meet the demands of the workplace and specific work tasks. (European Training Foundation).

- Ability to perform the required standards in the profession, in different circumstances. (British national body for qualification and certification - QCA).

- The application of knowledge, skills and behaviors that result in performance. (ISO 10015).

- Competencies are our knowledge, skills and attitudes that create our behavior in the workplace. 
Task of teams in Product Development is to achieve multiple compliance, exchange of information, to debate, dispute resolution and formal policies. It is important to establish the personal competencies, which are very important for the successful operation of the team. It is also important real competence, which team members have in relation to the upcoming task, only to be successfully solved. After extensive research in this direction, clearly defined following relevant competencies: professional competence, methodological competence, social competence, creative potential and ability elaboration. Furthermore will be defined the above mentioned competences.

Under social competences are following parameters or social behaviour and personal characteristics:

- Endurance

- Motivational parameters

0 initiatives

o work motivation

- Work styles

o Analytical way of thinking and working

o Orientation towards target

- Penetrability (the possibility of implementation)

- Problem solving

o Organizational skills

- Determination

o Determination of behaviour

- Creativity

- Team behaviour

o Cooperation

o Coordination

o Willingness to discuss

o Competence for discussion

- The behaviour in social situations

The term professional competencies include the practical knowledge and professional experience, as well as theoretical knowledge that an engineer in his own work use. It can be defined as "the willingness and ability to take on the basis of professional knowledge and skills of tasks and problems oriented towards a goal, if done correctly, methodically and independently solved and the results obtained adequate evaluation."

Methodical competence includes methods and proper procedures used by experienced specialists in resolving known and partially unknown problems.

Due to the accurate determination and a clear definition of professional and methodological competence, both competences are determined through answers to direct questions.

Social competence is more or less subjective but it is a very important factor, so it can not be easy determined. It can be determined through answers to indirect questions. There is difference between direct and indirect questions. In direct questions it is possible to estimate its own performance and skills of tested person. In indirect questions, tested persons are required to on the question choose between several possible answers. The rating is then performed through a personality test based on the long experience of psychologists. The team members are different personality types according to their personal and social characteristics.

Creative potential includes the following abilities:

- Sensitivity to problems,

- The appropriate use of creative techniques

- Availability of a large number of good ideas,

- Intellectual flexibility,

- Ability to abstract thinking.

Elaboration ability includes:

- Ability to achieve goals

- Orientation towards the customer,

- Keep in mind the requirements of the user,

- Knowledge of the consequences of costs and prices,

- Knowledge of the techniques of systematic work, 
- Durability in crisis situations,

- Enthusiasm in decision-making,

- A high level of tolerance.

\subsection{Authoritative competences of product development engineers}

Based on the above given, in Figures 1 is presented the authoritative competencies that need to gain as the primary product developers master's studies.

Figure 1: Authoritative competences in field Product Development on master studies

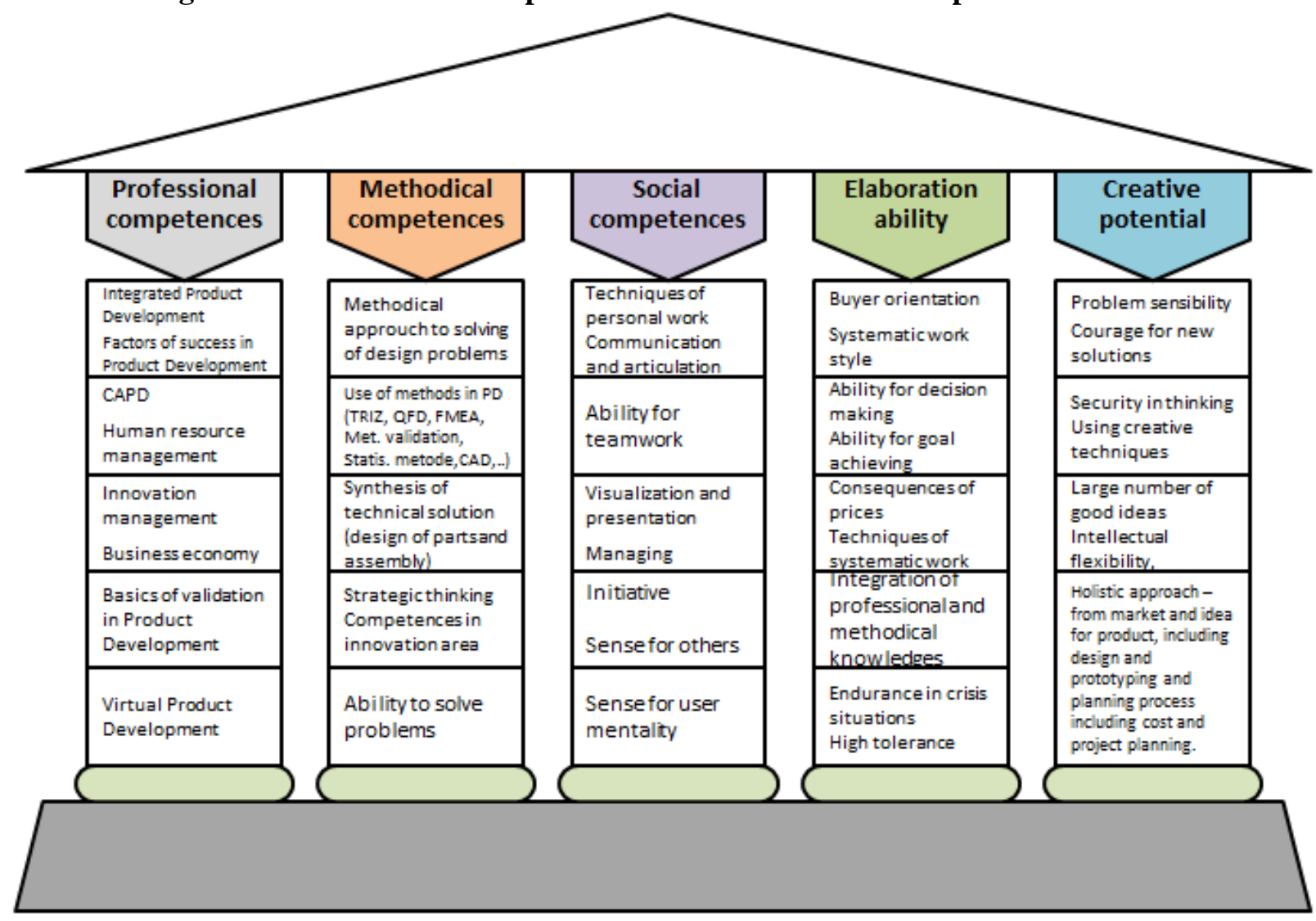

The main part of the education of product development engineers and acquiring of the necessary competencies are achieved during the master studies. Professional competence leaning on the knowledge acquired at the bachelor level are primarily oriented to obtain knowledge and skills in the areas of product development and the processes which are carried out at the same time. To acquire methodological competencies presented is the practical application of a number of methods to solve problems in Product Development, the ability to synthesize technical solutions, as well as the successful implementation of innovations. Social competences are focused on communication and articulation skills, teamwork and leadership as well as the ability to solve problems through their own initiatives. Very important are the competences related to the ability of elaboration. These competencies are expressed through the skills of systematic work style, integration of technical and methodological knowledge and managing in crisis situations. Competencies related to the creative potential include acquiring skills for applying creative techniques, safety at work and the implementation of new solutions as well as a holistic approach to product development.

\section{Conclusions}

The survival and success of modern companies can be provided through innovative products and manufacturing processes. However, the use of innovative products and manufacturing process is quite complex and requires a new approach to the work, which is primarily related to the optimization of available resources, the precise definition of competence and cooperative approach to work.

Innovations are a very important factor in the survival of the company at the market as they lead to the development of new high-quality products, the introduction of new technologies and the successful launch of products which enable companies to increase competitive ability. 
The most important role in the development of human resources have competences acquired during education and during professional career. Timely identification of authoritative competence has a very important impact on the successful execution of tasks in interdisciplinary project teams.

In this paper, clearly are defined the following relevant competence of product development engineers: professional competence, methodological competence, social competence, creative potential and ability elaboration. Based on a detailed analysis of the work presents authoritative competencies that product development engineers need to gain at master studies.

\section{References}

- Miltenović,V., Ianici,S., Banic,M., Miltenović,A.: University Teaching and Authoritative Competences of Product Development Engineers. Proc. of 8th International Symposium KOD 2014 Machine and Industrial Design in Mechanical Engineering, Balatonfüred, Hungary, (2014)

- Miltenović, V., Vereš, M., Banic, M.: Concept of virtual Product Development. Proceedings of 6th Int.Sym. about Forming and Design in mechanical Engineering - KOD 2010. (ISBN 978-86-7892278-7) Novi ad, Serbia, pp.7-12. (2012)

- Miltenović, V., Mitrović,R.: Ingenieurausbildung im Gebiet Produktentwicklung. Proceedings of the 7th International Scientific "Conference Research and Development of Mechanical Elements and Systems”, Zlatibor, Serbia. Plenary Session S. I-VI. (2011)

- Miltenović,V., Banic,M., Miltenović,A.: The New Engineering Education Model on University of Niš. Proceedings of the 4th International Conference on Power Transmissions, BAPT, Sinaia, Romania. pp.7-12. (2012)

- Miltenovic,V., Markovic,B., Banic,M., Miltenovic,A., Future Technology and Education of Engineers. Proc of 1st Int.Con. COMETa 2012, East Sarajevo - Jahorina, Bosnia and Herzegovina (2012).

- Binz, H., Albers, A., Universitäre Lehre in der Produktentwicklung. Leitfaden der Wissenschaftlichen Gesellschaft für Produktentwicklung (WiGeP). Stuttgart, Germany, (2013). 